\title{
Comparison of Visual Field Characteristics Between Normal Tension Glaucoma and Primary Open Angle Glaucoma
}

\author{
Shouvik Chattopadhayay ${ }^{1 *}$, Monica Choudhry ${ }^{2}$ and Shahiban Shethi ${ }^{3}$ \\ ${ }^{1}$ Assistant Professor, Teerthankar Mahaveer University, Moradabad, Uttar Pradesh, \\ India \\ ${ }^{2}$ Director, School of Health Science, Ansal University, Gurgaon, Haryana, India \\ ${ }^{3}$ Glaucoma Consultant, ADEH, Gurgaon, Haryana, India
}

*Corresponding Author: Shouvik Chattopadhayay, Assistant Professor, Teerthankar

Mahaveer University, Moradabad, Uttar Pradesh, India.
Received: March 23, 2021

Published: April 16, 2021

(C) All rights are reserved by Shouvik

Chattopadhayay., et al.

\begin{abstract}
Purpose: To compare pattern of visual field in cases of normal tension Glaucoma versus primary open angle Glaucoma.

Material and Methodology: This retrospective cross-sectional study was conducted in Aroonodaya Deseret eye hospital. We took their 40 Primary open angle glaucoma patients (of above 40 years and with no other systemic and medical problem) record with HVF report by their permission.

Results: In these 40 patients 20 has normal tension and 20 has high tension. Each of the 20 patients of HTG and NTG made a pair by their age matched, refractive error matched and Mean deviation matched. In NTG there are 10 male patient and 10 female patients in other hand in HTG there are 7 male and 13 female patients. According to the age there are 5 subgroups were made 1, 2, 3, 4 and 5; 41 - 50, $51-60,61-70,71-80$ and 81 - 90 respectively. The mean age \pm standard deviation was $64.2 \pm 12.3$ for the group of NTG and for the HTG it was $62.8 \pm 11.2$. So, there are no significant difference found in this study. In the case of PSD value which was analyzed age group wise was significant. Because the P value is 0.016 and when we had done the same test among the NTG and POAG sub groups in the basis of pattern deviation plot map; the $38^{\text {th }}$ point is significant which is actually placed under the blind spot and two points nasally. We had done GHT cluster analysis, there we found two points which were statistically significant these two significantly different points are ICL3b and ICL5b the P value of this points are 0.039 and 0.048 respectively. We had analyzed MD and PSD values on the basis of the stage of severity of the disease while the comparison of both the group together we found some significant difference. Conclusion: In conclusion, there are two parts. firstly, when we use the Pattern deviation map point wise analysis, we have got a difference in inferior paracentral area. The GHT wise analysis has shown the difference in inferior nasal step and in inferior scotomata area. And secondly, we can see MD wise analysis in mild to moderate, mild to severe and moderate to severe, and we got statistically significant differences. PSD value analysis has shown in NTG group a statistically significant difference in moderate to severe group. Similarly, in case of mild to moderate comparison, HTG group has shown the statistically significant difference.
\end{abstract}

Keywords: Visual Field; Normal Tension Glaucoma; Primary Open Angle Glaucoma

\section{Introduction}

Glaucoma is a general term that encompasses a range of ocular conditions causing a specific neuropathy of the optic nerve. It is the second leading cause of blindness in the world and can occur in all age groups, mostly common in the elderly. Glaucoma is characterized as progressive optic nerve damage associated with visual 
function loss. The most common clinical method of measuring the function of the visual system is the assessment of the eye's ability to detect the brightness of small points of light projected in both the central and peripheral areas of vision, also known as perimetry or visual field testing, standard automated perimetry (SAP). It is currently considered to be the gold standard for detecting glaucomatous visual field loss. It is called static perimetry, to determine functional glaucomatous changes. The defects, commonly referred to as scotomas, then begin to enlarge and follow the arcuate pattern of the retinal nerve fibers.

\section{Purpose of the Study}

To compare pattern of visual field in cases of normal tension Glaucoma versus primary open angle Glaucoma.

\section{Methodology}

This is a retrospective cross-sectional study which was conducted in Arunodaya Deseret eye hospital. 40 Primary open angle glaucoma patients (of above 40 years and with no other systemic and medical problem) record with HVF report. Among this 40 patients report, 20 has normal tension a high tension. Each of the 20 patients of HTG and NTG made nd 20 has a pair by their age matched, refractive error matched and Mean deviation matched.

\section{Inclusion criteria}

All primary open angle glaucoma patients and all normal tension glaucoma patients of above 40 years.

For each patient only the left eyes were included in this study.

\section{Exclusion criteria}

All angle closure glaucoma patients and secondary open angle glaucoma patients and all primary open angle glaucoma patient with any systemic disease or having any medical problem.

\section{Results}

In NTG there are 10 male patient and 10 female patients in other hand in HTG there are 7 male and 13 female patients. In the case of PSD value which was analyzed age group wise was significant. Because the P value is 0.016 . The test among the NTG and POAG sub groups in the basis of pattern deviation plot map; the $38^{\text {th }}$ point is significant ( $\mathrm{P}$ value is 0.008 ). GHT cluster analysis, two points which were statistically significant these two significantly different points are ICL3b and ICL5b the P value of this points are 0.039 and 0.048 respectively.

\section{Discussion}

The considerable disagreements in glaucoma community as to the possible difference in optic disc appearance and visual field

\begin{tabular}{|c|c|c|c|c|c|c|c|c|c|}
\hline $\begin{array}{c}\text { Multiple } \\
\text { comparison; } \\
\text { Bon ferroni }\end{array}$ & Group 1 & Group 2 & \begin{tabular}{|c|} 
p value of \\
NTG $(<0.05$ \\
is the level of \\
significancy)
\end{tabular} & $\begin{array}{l}\text { Lower } \\
\text { bound }\end{array}$ & $\begin{array}{l}\text { Upper } \\
\text { bound }\end{array}$ & $\begin{array}{c}\text { p value of poag }(<0.05 \\
\text { is the level of } \\
\text { significancy) }\end{array}$ & $\begin{array}{l}\text { Lower } \\
\text { bound }\end{array}$ & $\begin{array}{l}\text { Upper } \\
\text { bound }\end{array}$ & \\
\hline \multirow{6}{*}{ md } & \multirow{2}{*}{1} & 2 & 0 & 2.5137 & 6.4485 & 0 & 2.2692 & 7.5819 & \multirow{12}{*}{$\begin{array}{c}\text { Confidential } \\
\text { interval is } \\
95 \%\end{array}$} \\
\hline & & 3 & 0 & 18.7732 & 23.2348 & 0 & 18.904 & 24.928 & \\
\hline & \multirow{2}{*}{2} & 1 & 0 & & & 0 & -7.5819 & -2.268 & \\
\hline & & 3 & 0 & 14.5555 & 18.4903 & 0 & 14.3341 & 19.6468 & \\
\hline & \multirow{2}{*}{3} & 1 & 0 & -23.2348 & -187732 & 0 & -24.928 & -18.904 & \\
\hline & & 2 & 0 & -18.4903 & -14.5555 & 0 & -19.6468 & -14.3341 & \\
\hline \multirow{6}{*}{ psd } & \multirow{2}{*}{1} & 2 & 1 & -3.3016 & 3.62111 & 0.025 & -9.2622 & -0.5432 & \\
\hline & & 3 & 0.088 & -7.4408 & 0.4088 & 0.009 & -11.4172 & -1.5308 & \\
\hline & \multirow{2}{*}{2} & 1 & 1 & -3.2611 & 3.3016 & 0.025 & 0.5435 & 9.2622 & \\
\hline & & 3 & 0.036 & -7.1371 & -0.2144 & 1 & -5.9308 & 2.7882 & \\
\hline & \multirow{2}{*}{3} & 1 & 0.088 & -0.4088 & 7.4408 & 0.009 & 1.5308 & 11.4172 & \\
\hline & & 2 & 0.036 & 0.2144 & 7.1371 & 1 & -2.7882 & 5.9308 & \\
\hline
\end{tabular}

Table 1 


\begin{tabular}{|c|c|c|c|c|c|c|c|c|}
\hline & md ntg & Mean value & p value $(<0.05)$ & $\begin{array}{c}\begin{array}{c}\text { p value of md ntg } \\
(<0.05)\end{array} \\
\end{array}$ & psd ntg & $\begin{array}{l}\text { Mean } \\
\text { value }\end{array}$ & p value $(<0.05)$ & $\begin{array}{c}\text { p value of psd ntg } \\
(<0.05)\end{array}$ \\
\hline 1 & -2.5 & \multirow{6}{*}{-3.5533} & \multirow{6}{*}{0.471} & \multirow{20}{*}{0.368} & 3.06 & \multirow{6}{*}{5.47} & \multirow{6}{*}{0.219} & \multirow{20}{*}{0.368} \\
\hline 1 & -5.58 & & & & 4.81 & & & \\
\hline 1 & -3.16 & & & & 2.87 & & & \\
\hline 1 & -3.36 & & & & 11.65 & & & \\
\hline 1 & -4.9 & & & & 2.82 & & & \\
\hline 1 & -1.82 & & & & 7.61 & & & \\
\hline 2 & -9.73 & \multirow{9}{*}{-8.3811} & \multirow{9}{*}{0.061} & & 6.75 & \multirow{9}{*}{4.8822} & \multirow{9}{*}{0.061} & \\
\hline 2 & -10.65 & & & & 7.76 & & & \\
\hline 2 & -8.73 & & & & 5.52 & & & \\
\hline 2 & -9.36 & & & & 4.15 & & & \\
\hline 2 & -6.42 & & & & 5.87 & & & \\
\hline 2 & -7.34 & & & & 3.36 & & & \\
\hline 2 & -7.55 & & & & 4.34 & & & \\
\hline 2 & -9.4 & & & & 3.92 & & & \\
\hline 2 & -6.25 & & & & 2.27 & & & \\
\hline 3 & -17.08 & & & & 8.96 & & & \\
\hline 4 & -25.26 & \multirow{4}{*}{-25.08} & \multirow{4}{*}{0.18} & & 8 & \multirow{4}{*}{8.77} & \multirow{4}{*}{0.18} & \\
\hline 4 & -25.03 & & & & 9.14 & & & \\
\hline 4 & -25.83 & & & & 10.23 & & & \\
\hline 4 & -24.2 & & & & 7.71 & & & \\
\hline
\end{tabular}

Table 2

\begin{tabular}{|c|c|c|c|c|c|c|c|c|}
\hline & md poag & Mean value & $\begin{array}{l}\text { p value } \\
(<0.05)\end{array}$ & $\begin{array}{c}\text { p value of md poag } \\
(<0.05)\end{array}$ & psd poag & $\begin{array}{l}\text { Mean } \\
\text { value }\end{array}$ & $\begin{array}{l}\text { p value } \\
(<0.05)\end{array}$ & $\begin{array}{l}\text { p value of psd } \\
\text { poag }(<0.05)\end{array}$ \\
\hline 1 & -3.74 & \multirow{5}{*}{-3.39} & \multirow{5}{*}{0.284} & \multirow{20}{*}{0.392} & 2.82 & \multirow{5}{*}{2.684} & \multirow{5}{*}{0.284} & \multirow{20}{*}{ pelo } \\
\hline 1 & -2.61 & & & & 2.7 & & & \\
\hline 1 & -2.28 & & & & 2.08 & & & \\
\hline 1 & -2.87 & & & & 3.06 & & & \\
\hline 1 & -5.45 & & & & 2.76 & & & \\
\hline 2 & -7.94 & \multirow{9}{*}{-8.3156} & \multirow{9}{*}{0.447} & & 2.03 & \multirow{9}{*}{7.5867} & \multirow{9}{*}{0.212} & \\
\hline 2 & -7.47 & & & & 4.41 & & & \\
\hline 2 & -11.1 & & & & 8.43 & & & \\
\hline 2 & -10.56 & & & & 7.13 & & & \\
\hline 2 & -9.06 & & & & 11.55 & & & \\
\hline 2 & -6.31 & & & & 8.27 & & & \\
\hline 2 & -6.78 & & & & 12.87 & & & \\
\hline 2 & -7.37 & & & & 2.96 & & & \\
\hline 2 & -8.25 & & & & 10.63 & & & \\
\hline 3 & -12.08 & \multirow{2}{*}{-12.55} & \multirow{2}{*}{0.317} & & 9.14 & \multirow{2}{*}{7.12} & \multirow{2}{*}{0.317} & \\
\hline 3 & -13.02 & & & & 5.1 & & & \\
\hline 4 & -25.57 & \multirow{4}{*}{-24.9825} & \multirow{4}{*}{0.407} & & 6.28 & \multirow{4}{*}{9.34} & \multirow{4}{*}{0.407} & \\
\hline 4 & -26.65 & & & & 10.66 & & & \\
\hline 4 & -21.11 & & & & 11.99 & & & \\
\hline 4 & -26.6 & & & & 8.43 & & & \\
\hline
\end{tabular}

Table 3 
damage present in patient with HTG and NTG [1-17]. Michele Lester., et al. showed that there is no such difference in the visual field of HTG and NTG but in superior nasal step and inferior and superior scotomata areas have difference; field defect present in HTG than NTG [1]. Capriole and Spaeth showed that scotomas in NTG had a steeper slope were significantly closer to fixation compared to HTG and with a greater depth [3]. Many years earlier Bjerrums and Sjogren did not find any difference between these sub groups. Drance also did not find any different characteristics in visual field defect in those subgroups of glaucoma by using the Goldman Perimetry. Greve and Geijssen detected difference in the distribution of the visual field defects between HTG and NTG but in later the larger defects were more frequently in the upper half of the visual field [1]. There are so many studies possibly find in the literature, and some anthers believed that HTG and NTG have different visual field defect and Optic Nerve Head damage while other researchers were found no difference in Optic disc and visual field in these two sub-groups of glaucoma.

The different findings of the visual field of this subgroup of glaucoma relate particularly NTG which is usually detected only when Optic Nerve Head damage has already occurred; in other word when significant visual field impairment is present. But in the case of HTG patients are mainly detected through high IOP. The NTG patients are attended the practitioner at the time when the visual acuity is hampered for the extension or very close position of scotoma to fixation point. That's why the NTG is more harmful than HTG and it may be one of the causes of different variation of visual field. In this study we analyzed the 54 points of visual field report of HTG and NTG patients, but there is no significant difference present in sensitivity map but in pattern deviation map there is significant difference is present in one point only which is placed one point inferior and two point towards nasally of the blind spot.

Although there is no point wise difference present statistically between NTG and HTG. We had point out three statistical consideration; first, when so many numbers are tested and compared for a chance it is possible to find some points with significant difference, just because of mathematical probability; second if we applied the binominal test to the pattern of mean changes across the points and the test assumed the point data were mutually independent under the hypothesis of zero difference, the positive and negative points are equal; third if we analyzed the PSD value between HTG and NTG on the basis of Mild or Early, Moderate, Advanced, Severe, there might be some statistical difference found by the testing of this two (NTG and HTG) independent groups. When GHT areas were compared between HTG and NTG some difference was found in 30degree inferior nasally from fixation point and 30-degree inferior to the fixation point. There are no statistical differences found in paracentral area.

Arie., et al. analyzed the visual field point wise and found different field morphology between NTG and HTG. They suggested that different $\mathrm{ONH}$ regions could be more susceptible to damage in NTG but Michel Lester., et al. analyzed point wise and GHT cluster wise and found completely differently field morphology between NTG and HTG, they suggested that there is difference in paracentral areas, but superior nasal step and inferior and superior scotomata showed to be deeper in the HTG and NTG [9]. Our sample was different from previous studies but there is no statistically significant difference between the two groups. In our study central corneal thickness and IOP is not analyzed. We divided the POAG groups in to two sub groups (NTG and HTG) on the basis of IOP and gonio structure $[20,21]$. Here after the analysis of the all data which is point wise, GHT cluster wise and MD and PSD (based on Mild, Moderate, Advanced and Sever) wise [18-24]. We got a result which tells us there is no statistically significant difference. But in age wise PSD value comparison of NTG sub group shows a significantly difference and if we go through a point wise analysis a $38^{\text {th }}$ point of pattern deviation map has a significant difference, which is present in paracentral area and if we look GHT analysis report we can see a difference in inferior cluster 3 and 5 which present in nasal steep and inferior peripheral area respectively. At the end if we discuss about MD and PSD wise analysis report we can see there only MD wise differences are present. There we compare mile to moderate and mild to severe and moderate to severe and we got statistically significant difference. Here if we analyzed PSD value then in NTG group moderate to severe group but in case of mild to moderate comparison of HTG group can show the statistically significant difference.

\section{Conclusion}

In conclusion, there are two parts:

- Firstly, the Pattern deviation map point wise analysis, got a difference in inferior paracentral area, the GHT wise analysis has shown the difference in inferior nasal step and in inferior scotomata area.

- Secondly MD wise analysis in mild to moderate, mild to severe and moderate to severe, got statistically significant differences. PSD value analysis has shown in NTG group a statistically significant difference in moderate to severe group. In case of mild to moderate comparison, HTG group has shown the statistically significant difference. 


\section{Bibliography}

1. Iester M., et al. "Visual field loss morphology in high-and normal-tension glaucoma”. Journal of Ophthalmology (2012).

2. Anderton S and Hitchings RA. "A comparative study of visual fields of patients with low-tension glaucoma and those with chronic simple glaucoma". In Fifth International Visual Field Symposium (1983).

3. Greve EL and Geijssen HC. "The relation between excavation and visual field in glaucoma patients with high and with low intraocular pressures". In Fifth International Visual Field Symposium (1983).

4. Caprioli J and Spaeth GL. "Comparison of visual field defects in the low-tension glaucoma's with those in the high-tension glaucoma's". American Journal of Ophthalmology (1984).

5. Caprioli J and Spaeth GL. "Comparison of the optic nerve head in high-and low-tension glaucoma". Archives of Ophthalmology (1985).

6. Chauhan BC., et al. "Visual field damage in normal-tension and high-tension glaucoma”. American Journal of Ophthalmology (1989).

7. Drance SM., et al. "Diffuse visual field loss in chronic open-angle and low-tension glaucoma". American Journal of Ophthalmology (1987).

8. Fazio P., et al. "Primary Open Angle Glaucoma”. Archives of Ophthalmology (1990).

9. Yamagami J., et al. "A comparative study of optic nerve head in low-and high-tension glaucoma's". Graefe's Archive for Clinical and Experimental Ophthalmology (1992).

10. Tuulonen A and Airaksinen PJ. "Optic disc size in exfoliative, primary open angle, and low-tension glaucoma". Archives of Ophthalmology (1992).

11. Samuelson TW and Spaeth GL. "Focal and diffuse visual field defects: their relationship to intraocular pressure". Ophthalmic Surgery, Lasers and Imaging Retina (1993).

12. Motolko M., et al. "The visual field defects of low-tension glaucoma”. In Fifth International Visual Field Symposium (1983).

13. Lewis RA., et al. "Optic disk and visual field correlations in primary open-angle and low-tension glaucoma". American Journal of Ophthalmology (1983).
14. Motolko M., et al. "Visual field defects in low-tension glaucoma: comparison of defects in low-tension glaucoma and chronic open angle glaucoma". Archives of Ophthalmology (1982).

15. Poinoosawmy D., et al. "Frequency of asymmetric visual field defects in normal-tension and high-tension glaucoma1". Ophthalmology (1998).

16. Chu DH., et al. "Patterns of visual field abnormalities in normal versus high tension glaucoma". Investigative Ophthalmology and Visual Science (2004).

17. Iester $M$ and Mikelberg FS. "Optic nerve head morphologic characteristics in high-tension and normal-tension glaucoma". Archives of Ophthalmology (1999).

18. Drance S., et al. "Risk factors for progression of visual field abnormalities in normal-tension glaucoma". American Journal of Ophthalmology (2001).

19. Thonginnetra 0., et al. "Normal versus high tension glaucoma: a comparison of functional and structural defects". Journal of Glaucoma (2010).

20. Kim M., et al. "Lamina depth and thickness correlate with glaucoma severity". Indian Journal of Ophthalmology (2016).

21. "Parson's Disease of the Eye". 19 ${ }^{\text {th }}$ Edition, Ramanjit Sihota, Radhika Tandon.

22. Glaucoma, Basic and Clinical Science Course, Section10,2000-2001". The American Academy of Ophthalmology.

23. Visual fields via the visual pathway, Fiona Rowe.

24. Hodapp E. "The asymptomatic patient with elevated pressure". Clinical Decisions in Glaucoma (1993).

\section{Assets from publication with us}

- Prompt Acknowledgement after receiving the article

- Thorough Double blinded peer review

- Rapid Publication

- Issue of Publication Certificate

- High visibility of your Published work

Website: www.actascientific.com/

Submit Article: www.actascientific.com/submission.php Email us: editor@actascientific.com

Contact us: +919182824667 